\title{
The misfolded pro-inflammatory protein S100A9 disrupts memory via neurochemical remodelling instigating an Alzheimer's disease-like cognitive deficit
}

\author{
Marina A. Gruden ${ }^{1}$, Tatiana V. Davydova ${ }^{2}$, Chao Wang ${ }^{3}$, \\ Victor B. Narkevich ${ }^{4}$, Valentina G. Fomina ${ }^{2}$, Vladimir S. Kudrin ${ }^{4}$, \\ Ludmilla A. Morozova-Roche ${ }^{3}$, Robert D. E. Sewell $*^{5}$
}

${ }^{1}$ Federal State Budgetary Scientific Institution "P. K. Anokhin Research Institute of Normal Physiology", Moscow, Russia

${ }^{2}$ Federal State Budgetary Scientific Institution "Research Institute of General Pathology and Pathophysiology", Moscow, Russia ${ }^{4}$

${ }^{3}$ Department of Medical Biochemistry and Biophysics, Umeå University, Umeå, SE-90187, Sweden.

${ }^{4}$ Federal State Budgetary Scientific Institution "V. V. Zakusov Research Institute of Pharmacology, Moscow, Russia.

${ }^{5}$ Cardiff School of Pharmacy and Pharmaceutical Sciences, Cardiff University, Cardiff, CF10 3NB, U.K.

Short title: Misfolded S100A9 impairs memory

Keywords: S100A9, amyloid, neuroinflammation, memory, passive avoidance task, neurotransmitters, Alzheimer's disease

*Corresponding author Robert Sewell at: Cardiff School of Pharmacy and Pharmaceutical Science, Cardiff University, Redwood Building, King Edward VII Ave., Cathays Park, Cardiff CF10 3NB, UK. Tel +44 (0)2929 875821 E-mail address: sewell@cardiff.ac.uk (Professor R. D. E. Sewell) 


\begin{abstract}
Memory deficits may develop from a variety of neuropathologies including Alzheimer's disease dementia. During neurodegenerative conditions there are contributory factors such as neuroinflammation and amyloidogenesis involved in memory impairment. In the present study, dual properties of S100A9 protein as a pro-inflammatory and amyloidogenic agent were explored in the passive avoidance memory task along with neurochemical assays in the prefrontal cortex and hippocampus of aged mice. S100A9 oligomers and fibrils were generated in vitro and verified by AFM, Thioflavin T and A11 antibody binding. Native S100A9 as well as S100A9 oligomers and fibrils or their combination were administered intranasally over 14 days followed by behavioural and neurochemical analysis. Both oligomers and fibrils evoked amnestic activity which correlated with disrupted prefrontal cortical and hippocampal dopaminergic neurochemistry. The oligomer-fibril combination produced similar but weaker neurochemistry to the fibrils administered alone but without passive avoidance amnesia. Native S100A9 not modify memory task performance even though it generated a general and consistent decrease in monoamine levels (DA, 5-HT and NA) and increased metabolic marker ratios of DA and 5-HT turnover (DOPAC/DA, HVA/DA and 5-HIAA) in the prefrontal cortex. These results provide insight into a novel pathogenetic mechanism underlying amnesia in a fear-aggravated memory task based on amyloidogenesis of a pro-inflammatory factor leading to disrupted brain neurochemistry in the aged brain. The data further suggests that amyloid species of S100A9 create deleterious effects principally on the dopaminergic system and this novel finding might be potentially exploited during dementia management through a neuroprotective strategy.
\end{abstract}




\section{Introduction}

There is now growing evidence suggesting that in Alzheimer's disease (AD) neuroinflammation is one of the cardinal pathogenic features accompanied by the accumulation of amyloid- $\beta$ protein $(\mathrm{A} \beta)$ in extracellular plaques and deposition of hyperphosphorylated tau protein in intracellular neurofibrillary tangles [1-3]. Furthermore, AD has largely been characterized by a severe deterioration of cognitive function [4] but the causal cellular and molecular mechanisms of cognitive decline are still subject to debate and endeavour [5,6]. Some members of the $\mathrm{S} 100$ protein group of which there are $\leq 24$ examples [7,8] such as S100B [9,10], S100A1 [11], S100A8, S100A9 and the S100A8/A9 complex [12] are thought to be implicated in $\mathrm{AD}$ pathogenesis [13]. It is also noteworthy that S100A8/S100A9 and its complex are recognised as potent stimulators of neutrophil migration into inflammatory sites [14]. Explicitly in neural tissues, S100A9 protein is understood to modulate inflammation because it is prevalent within neuritic plaques as well as reactive glia and these days, it is continuously acknowledged as an influential contributor to inflammation-linked neurodegenerative states like AD [12,15,16]. Accordingly, it has been demonstrated that S100A9 brain expression is increased not only in AD mouse models but also in human AD sufferers [12]. The instrumental role of inflammation in $\mathrm{AD}$ is further supported by a sharp induction of inflammatory mediators in AD-affected brains [17] in addition to epidemiological and experimental studies which demonstrate that non-steroidal anti-inflammatory drugs markedly reduce the age-related prevalence of AD [18]. Since S100A9 is highly abundant in AD brains, it may well be a key element in AD progression due to its inherent amyloidogenicity [16,19] and it has been reported that intrinsically disordered prone molecular regions underlie $\beta$-aggregation of the S100 proteins [20].

The amyloid pathway is known to play a crucial role in AD pathogenetic processes [21] so the discovery that S100A9 is abundant in tissues surrounding amyloid deposits in AD brains is highly suggestive that an elevation of S100A9 levels favours its aggregation and deposition [16]. In animal studies, evidence has been presented that the inflammation-related S100A9 gene is significantly up-regulated in the brains of Tg2576 and CT-Tg AD mouse models as well as in AD patients. In addition, experiments have shown that knockdown of S100A9 expression improves cognitive function in the Tg2576 AD mouse and these animals correspondingly exhibit a reduced amyloid plaque burden [22]. Moreover, crossbreeding of Tg2576 mice with S100A9 knockout mice (S100A9KO/Tg2576) enhances visuospatial 
reference memory and diminishes $A \beta$ neuropathogenesis as evidenced by reduced levels of A $\beta$, C-terminal fragments of amyloid precursor protein (APP-CT) and phosphorylated tau compared to age-matched S100A9WT/Tg2576 controls. Commensurate with these findings, there was an increase in expression of anti-inflammatory IL-10 and decreased expression of inflammatory interleukin 6 as well as tumour necrosis factor- $\alpha$ [23]. These results clearly show that the up-regulation of the S100A9 gene plays an important role in the neuropathology and memory impairment in $\mathrm{AD}$ [12] as well as the neurodegeneration and cognitive deficits seen in $\operatorname{Tg} 2576$ mice [23].

In addition, AD pathology is even more intricate since in parallel with neuroinflammation and protein neuroaggregation, there are consequentially perturbed neurotransmitter signalling processes [24]. Thus, studies have disclosed links between morphological and functional changes occurring in ascending monoaminergic systems such as noradrenergic and serotonergic pathways with respect to AD pathophysiology [25,26]. In association with symptoms of cognitive decline, about $35-40 \%$ of AD patients present with extrapyramidal signs, reinforcing the idea that dopamine (DA) containing neurons undergo degenerative changes [24,27]. Furthermore, the use of dopaminergic D2 agonist drugs like rotigotine, have manifested beneficial effects on some cognitive domains in AD patients [28]. What is more, changes in various correlates of cholinergic, monoaminergic and amino acid neurotransmitter systems, as well as neuropeptides, have recently been appraised in the CSF of $\mathrm{AD}$ patients [29].

Information concerning potential interactions of S100A9 amyloid species with neurotransmitter pathways is unavailable in the literature although it is known that native S100A9 interacts with $A \beta_{(1-40)}$ peptide and promotes the formation of fibrillar $\beta$-amyloid structures [30]. Protofilaments of S100A9 themselves are highly neurotoxic and inflict rapid damage and death to neurons. Due to the fact that combined aggregation of S100A9 with A $\beta$ peptide proceeds more efficiently than the separate counterparts, the co-aggregation process may act as an emergency sink, rapidly removing systemic neurotoxic amyloid species of both polypeptides. On top of this, native S100A9 is a ligand at both Toll-like receptors (TLRs) and the receptor for advanced glycation end products (RAGE), the latter being involved in the recognition of endogenous molecules released during chronic inflammation $[16,31,32]$. The consequence of this clearance process however, can be the exacerbated growth of amyloid plaques in the AD brain. It is known from previous studies that amyloid 
complexes of S100A9 are much more stable and protease resistant compared to amyloid species of other proteins [33] and their clearance and removal may be therapeutically less favorable. Furthermore, the plaques themselves may aggravate microglial activation, thus completing a vicious circle of the amyloid-neuroinflammatory cascade [16]. On the other hand, the formation of amyloid plaques may act as a depository for toxic species, and the process may derive from of a protective response within the brain of $\mathrm{AD}$ patients, in part mediated by S100A9 itself [30]. It is clear that because of its amyloidogenic propensity, neurotoxicity and signalling functions, native S100A9 and its misfolded species may be capable not only of modifying memory and learning processes but also of impairing them via a pro-inflammatory origin. The aim of this study therefore was primarily to investigate the effects of exogenous intranasal administration of native S100A9 as well as in vitro generated oligomers and fibrils or their combination on passive avoidance learning and memory along with monoamine neurotransmitter metabolism in cerebral structures of aged mice.

\section{Materials and Methods}

\subsection{Subjects}

Adult male C57B1/6 mice aged 12-months and weighing 31.1 $1.0 \mathrm{~g}$ were used throughout. The animals were group housed on a 12:12 light-dark cycle at a constant temperature of $21^{\circ} \mathrm{C}$ and $50 \%$ humidity with access to food and water ad libitum. All experimental procedures were carried out in accordance with the National Institute of Health Guide for the Care and Use of Laboratory Animals (NIH Publications No. 80-23, revised 1996); the UK Animals Scientific Procedures Act 1986 and associated guidelines; the European Communities Council Directive of 24 November 1986 (86/609/EEC) for care and use of laboratory animals. They were also approved by the Animal Care and Use Committee of the P. K. Anokhin Research Institute of Normal Physiology. 


\subsection{Procedures and dosing protocol}

Experiments were performed between 10.00-15.00 hours and animals were divided into five groups ( $\mathrm{n}=14$ per group) which underwent the protocol chronology shown in Fig. 1. (Group 1; naïve control) was administered saline vehicle intranasally (i.n) in alternate nostrils daily in a total volume of $8 \mu \mathrm{L} / \mathrm{animal}$ daily (i.e. $4 \mu \mathrm{L} /$ nostril using a Hamilton syringe) over a total dosing period of 14-days. Group (2) was administered a solution of native S100A9 (15.0 $\mu \mathrm{g}$ in $8 \mu \mathrm{L}=0.48 \mathrm{mg} / \mathrm{kg}$ ) using the same 14-day dosing schedule. Group (3) received oligomeric aggregates $(15.0 \mu \mathrm{g}$ in $8 \mu \mathrm{L}=0.48 \mathrm{mg} / \mathrm{kg})$ using the 14-day dosing schedule. Group (4) was dosed with S100A9 fibrillar aggregates $(15.0 \mu \mathrm{g}$ in $8 \mu \mathrm{L}=0.48 \mathrm{mg} / \mathrm{kg})$ for 14 days. Group (5) was co-administered aggregates of S100A9 oligomers plus fibrils simultaneously each in a 50\%:50\% concentration of $7.5 \mu \mathrm{g}$ in $4 \mu \mathrm{L} /$ animal bilaterally alternating the nostril receiving each aggregate species (i.e. total $\alpha$-syn equivalent dose 15 $\mu \mathrm{g}=0.48 \mathrm{mg} / \mathrm{kg}$ i.n.) over the 14-day protocol. At the end the 14-day protocol (i.e. on day 15), animal groups 1-5, underwent behavioral testing. The next day they were killed and neurochemical analysis of the hippocampus and prefrontal cortex was performed $(n=7$ per group). All behavioral tests and neurochemical analyses were performed under blind conditions.

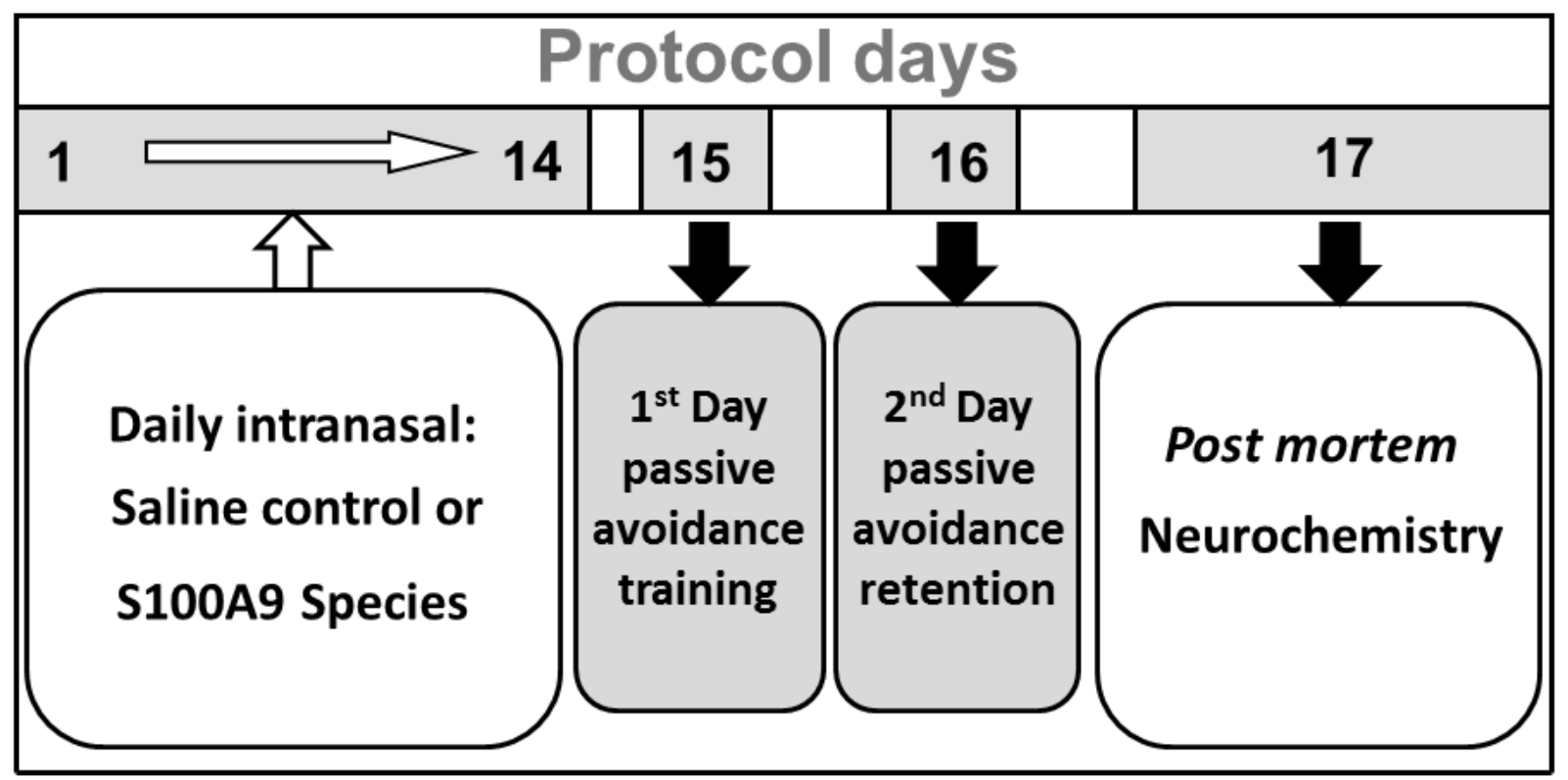

Fig. 1. Scheme showing the chronology of the intranasal S100A9 dosing protocol, passive avoidance training and retention sessions then the post mortem hippocampal and prefrontal cortical sampling period in 12-month old C57Bl/6 mice prior to neurochemical analysis. 


\subsection{Production of S100A9 protein}

S100A9 was expressed in E coli and purified as described previously [34]. Its concentration was determined by using $\varepsilon 280=0.53(\mathrm{mg} / \mathrm{ml})^{-1} \mathrm{~cm}^{-1}$.

\subsection{Production of S100A9 amyloid species}

In order to avoid the presence of the preformed aggregates in S100A9 solution, the protein was initially dissolved in $10 \mathrm{mM}$ PBS buffer, $\mathrm{pH} 7.4$, subjected to $15 \mathrm{~min}$ sonication, then to 15 min centrifugation at 14,000 rpm in a minicentrifuge (Eppendorf Centrifuge 5417R) and the supernatant collected from the upper layer was filtered through a 0.22 um filter (Millex). The final solution was incubated at a $2.0 \mathrm{mg} / \mathrm{ml}$ concentration in $10 \mathrm{mM}$ PBS buffer, $\mathrm{pH} 7.4$, $37{ }^{\circ} \mathrm{C}$, using continuous agitation at $600 \mathrm{rpm}$ (Eppendorf Thermomixer Compact). Amyloid oligomers and fibrils of S100A9 were produced after $2 \mathrm{~h}$ and $24 \mathrm{~h}$ of incubation, respectively. The oligomeric sample was lyophilized for storage and reconstituted in PBS buffer prior to dosing while the fibrillar sample was stored at $4{ }^{\circ} \mathrm{C}$ prior to administration. The morphological parameters of reconstituted oligomers were compared with freshly produced structures using AFM imaging and they were confirmed to be essentially unchanged.

\subsection{Fluorescence assay}

The Thioflavin $\mathrm{T}$ (ThT) binding assay was performed using a modification of LeVine's method [35]. Thioflavin $\mathrm{T}$ fluorescence was measured by a Jasco FP-6500 spectrofluorometer (Jasco, Japan), using excitation at $440 \mathrm{~nm}$ and collecting the emission between $450-550 \mathrm{~nm}$, with excitation and emission slits set at a $5 \mathrm{~nm}$ width.

\subsection{Atomic force microscopy (AFM) assay}

Atomic force microscopy (AFM) imaging was carried out by a BioScope Catalyst AFM 
(Bruker) in the peak force mode in air at a resonance frequency of ca. $70 \mathrm{kHz}$ and a resolution of 256 x 256 pixels; scan sizes ranged from 0.5 to $10 \mu \mathrm{m}$. Amyloid samples were deposited on the surface of freshly cleaved mica (Ted Pella) for $15 \mathrm{~min}$, washed 3 times with $100 \mu \mathrm{l}$ deionized water and dried at room temperature and then subjected to AFM analysis (Fig. 2).

\subsection{Behavioural tests}

\subsubsection{Passive avoidance test}

Behavioral analysis was performed in all animal groups ( $\mathrm{n}=14$ per group) one day after the end of the native S100A9 or its amyloidgenic species dosing protocol (i.e. day 15). Passive avoidance performance was investigated using a training apparatus which consisted of a rectangular chamber divided into two compartments (PACS two-way Shuttle box, Columbus Instruments, USA). One compartment was lit by an overhead light stimulus and the other side remained in darkness. The two compartments were separated by an automatic guillotine door and each had a grid floor through which footshock could be delivered. One-trial passive avoidance tests were performed as previously described [36,37]. Briefly, each animal was introduced singly into the light compartment of the light-dark box. During habituation, mice were allowed to freely explore the box for $5 \mathrm{~min}$ with the sliding door between the light and dark compartments open and subsequently, they were returned to their home cage. On the training day, each animal was placed into the lit compartment, facing away from the dark compartment and allowed to explore for 30s then the guillotine door was lifted. Upon animal entry into the dark compartment with all four paws, the guillotine door was then closed, and the entry latency recorded (from the time the door was lifted). Three seconds after door closure, a footshock $(0.5 \mathrm{~mA}, 3$ seconds duration) was delivered and $30 \mathrm{~s}$ later each mouse was removed to its home cage. Animals which did not enter the dark compartment within 180s underwent another session of training on the same day. Tests were carried out $24 \mathrm{~h}$ after conditioning by re-introducing animals into the light compartment of the apparatus and the latency of mice entering the dark compartment was recorded (lightdark latency, with a 5 min cut-off). The $24 \mathrm{~h}$ postconditioning tests were carried out in all experimental animal groups. 


\subsubsection{Open field exploratory test}

Animal behavioral analysis was performed on all groups $(n=10)$ one day following the S100A9 species and control dosing protocols (i.e. day 15) and a total of five behavioral indicators of emotionality as well as qualitative and quantitative measures of general locomotor activity were evaluated [38,39]. Firstly, hypokinesia was assessed by quantifying open field spontaneous locomotor activity based on previous methodologies [40,41] for a period of 0-6 min after $5 \mathrm{~min}$ acclimatization in an animal activity meter (Opto-Variomex-3 Auto-Track system, Columbus Instruments, Columbus, Ohio, USA). The 0-6 min recording time was chosen since it represented an optimal period for detecting neurotoxin-induced locomotor hypokinesia in 3-minute epochs up to a total of 30 minutes in C57Bl/6 mice [42]. Additionally, total locomotor distance, cumulative ambulation time plus speed (horizontal activity measures) and vertical rearing (vertical activity measure) along with immobility time were recorded. Secondly, muscle rigidity was gauged using a "gibbosity" test manifested by the shortening of the neck to the tailbase measurement and scored by the following scoring scale: $(0)=$ no rigidity; $(1)=1.0 \mathrm{~cm}$ decrease $;(2)=2.0 \mathrm{~cm}$ decrease; $(3)=>2.0 \mathrm{~cm}$ decrease [42]. Thirdly, the presence or absence of tremor was checked behaviourally [43] using the following scoring scale: $(0)=$ no tremor; $(1)=$ head tremor; $(2)=$ head and forepaw tremor, (3) = whole body tremor. Lastly, assessment of anxiety-like behavior was also included in the form of a fecal boli count for all groups [44].

\subsection{Neurochemical determination of the tissue content of DA, 5-HT and their metabolites} (DOPAC, HVA and 5-HIAA as well as NA in mouse brain structures by high performance liquid chromatography with electrochemical detection (HPLC/ED)

Hippocampal and prefrontal cortical mouse brain structures were dissected on ice $\left(4^{0} \mathrm{C}\right)$ then weighed and immediately stored in liquid nitrogen for subsequent analysis. Tissue samples were homogenized in $0.1 \mathrm{~N}$ perchloric acid (1:20) with $0.5 \mu \mathrm{M}$ 3,4-dihydroxybenzoic acid as internal standard and centrifuged (10,000g x $10 \mathrm{~min}, 4^{0} \mathrm{C}$; Eppendorf $5415 \mathrm{R}$, Germany). The supernatant was analyzed by high performance liquid chromatography with electrochemical detection (HPLC/ED) [45]. DA and its metabolites, DOPAC, and HVA as well as 5-HT, 5-HIAA and NA were detected using a glassy carbon electrode set at $+0.85 \mathrm{~V}$ compared with an $\mathrm{Ag} / \mathrm{AgCl}$ reference electrode using an electrochemical detector LC4B (Bioanalytical Systems, West Lafayette, Indiana, USA). The mobile phase contained 0.1 M citrate-phosphate buffer ( $\mathrm{pH}$ 2.9), $1.85 \mathrm{mM}$ 1-octanesulfonic acid, $0.27 \mathrm{mM}$ 
ethylenediaminetetra-acetate (EDTA) and $8 \%$ acetonitrile and $\mathrm{pH}$ was adjusted to 3.0 with $6 \mathrm{M} \mathrm{KOH}$. All reagents used for the mobile phase were of analytical grade (Sigma-Aldrich, USA) and samples were filtered through a $0.22 \mu \mathrm{m}$ nylon filter (Merck Millipore, Merck KGaA, Germany). DA, 5-HT and their metabolites as well as NA were separated by an analytical reverse-phase column on reprosil C18, pore size $4 \mu \mathrm{m}, 100 \times 4 \mathrm{~mm}$. (Dr. Maisch, GMBH) at a flow rate of $1.0 \mathrm{ml} / \mathrm{min}$.

\subsection{Statistics}

Results were statistically processed using Statistica 7.0 software. The distribution of behavioral data did not conform to a normal distribution (Lilliefors test, $P<0.01$ ) and thus, univariate nonparametric analysis of variance Kruskal-Wallis test (H-criterion) with by posthoc analysis by the Mann-Whitney $U$ test was performed. Data are presented as mean \pm s.e.m. The critical level of statistical significance in the test for the null hypothesis was accepted at $P<0.05$.

\section{Results}

\subsection{Characterization of S100A9 oligomeric and fibrillar aggregates}

The samples containing S100A9 oligomers were collected after $2 \mathrm{~h}$ of incubation. They were characterized by a 1.3-fold increase in Thioflavin $\mathrm{T}$ fluorescence compared to freshly dissolved native S100A9. The oligomers of S100A9 displayed a round-shaped morphology assessed by AFM imaging with an average height measured by AFM cross-section analysis of 1.0nm (Fig. 2A, B). Some small and coiled protofilaments of ca. $100 \mathrm{~nm}$ in length were also noticed in the sample, some of them were locked into ring-type structures of a 50 to 100 $\mathrm{nm}$ diameter. Fibrillar structures were developed after $24 \mathrm{~h}$ of incubation under the same conditions. They displayed typical fibrillar morphology with ca. $3 \mathrm{~nm}$ height as determined in AFM cross-sections (Fig. 2C, D) and were characterized by a 5.6-fold increase in Thioflavin $\mathrm{T}$ fluorescence intensity (Fig. 2E). The S100A9 fibrils were very flexible and coiled, existing separately and also coiled into some superstructured coils and clumps. The oligomeric nature of these species was verified by interaction with generic A11 antibodies 
reactive towards S100A9 amyloid oligomers and fibrils [46].
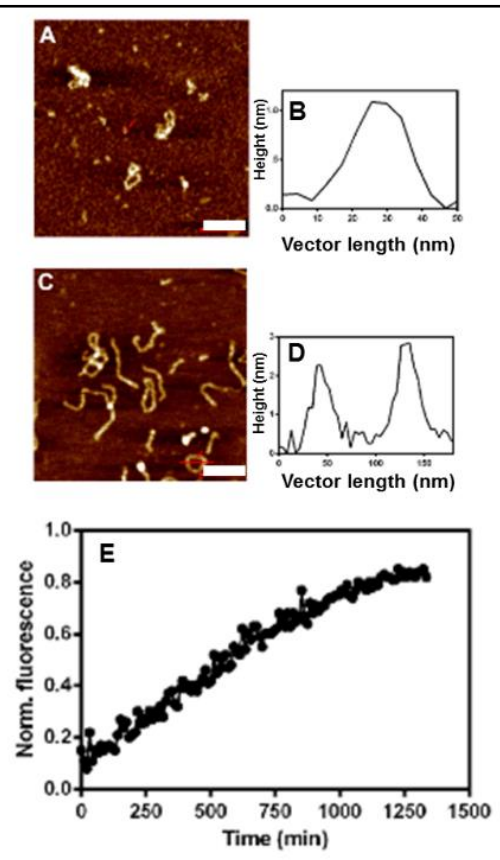

Fig. 2. In vitro characterisation of S100A9 amyloid species

AFM height images of S100A9 amyloid (A) oligomers and (C) fibrils formed after $2 \mathrm{~h}$ and $24 \mathrm{~h}$ of incubation under the same conditions, Scale bars are both $220 \mathrm{~nm}$.

Cross-sectional analysis of representative amyloid (B) oligomers and (D) ring-type fibrils. (E) Thioflavin T fluorescence intensity of S100A9 amyloid development with respect to time ( $\mathrm{min}$ ).

\subsection{Behavioural data}

3.2.1. Passive avoidance performance of aged mice treated intranasally (i.n.) with saline vehicle, native S100A9, oligomers, fibrils and an oligomeric plus fibrillar mixture for 14 days

The passive avoidance performance activity of mice treated for 14-day i.n. with native S100A9, oligomers, fibrils and the oligomer/fibrillar mixture in comparison with saline vehicle treated controls is shown in Fig. 3. There was a $+343.5 \%(\mathrm{P}<0.01)$ increase in latency in the retention session compared to the first day training session in the control group.

In the native S100A9 treated group, there was no statistical difference in mean latencies versus the control group retention latency or the difference $(\Delta)$ between first day and retention day latencies. However, in the group administered S100A9 oligomers, the first day latency was 2.56 fold higher than the controls and this latency persisted during retention such that the 
$\Delta$ latency was markedly lower than controls $(\mathrm{P}<0.01)$. A similar outcome was observed in the S100A9 fibril dosed group in that there was a highly significant $\Delta$ latency difference $(\mathrm{P}<0.01)$ from the vehicle treated controls. In the case of animals receiving the oligomeric/fibrillar mixture there was no difference from controls throughout (Fig. 3). Analysis of variance for the passive avoidance task latency on the 1st training day revealed a statistically significant difference between animal groups after 14 day intranasal inoculation with native S100A9, S100A9 aggregates or their mixture in comparison with the control group $(\mathrm{H}(4 \mathrm{~N}=50)=15.84345, P=0.0032)$. On the 2 nd day (retention) analysis of variance for the passive avoidance task latencies between experimental groups and controls disclosed significance $(\mathrm{H}(4 \mathrm{~N}=50)=9.807386, P=0.0438)$ and in addition, evaluation of passive avoidance $\Delta$ latencies versus controls also yielded significance $(\mathrm{H}(4 \mathrm{~N}=50)=27.17050$, $P<0.001)$.

\subsubsection{Open field exploratory activity of aged mice treated intranasally (i.n.) with saline vehicle, S100A9 oligomers or fibrils for 14 days}

After 14 day intranasal treatment with saline vehicle and S100A9 oligomers or fibrils, no significant behavioral differences between the S100A9 species treated group responses versus control were detected in total locomotor distance $(\mathrm{H}(2, \mathrm{~N}=30)=2.006947 \quad(P=0.3666)$, cumulative ambulation time $(\mathrm{H}(2, \mathrm{~N}=30)=3.829396(P=0.1474)$, immobility time $(\mathrm{H}(2$, $\mathrm{N}=30)=4.761425(P=0.0925)$, ambulation speed $(\mathrm{H}(2, \mathrm{~N}=30)=2.029224(P=0.3625)$ or vertical rearing $(\mathrm{H}(2, \mathrm{~N}=30)=0.8797098(P=0.6441)($ Table 1$)$. Neither was there evidence of rigidity identified in any of the groups using the established scoring scale and none of the animals exposed to the open field paradigm displayed any significant differences in fecal boli counts. Thus, it was confirmed that intranasal administration of the S100A9 aggregates was devoid of any anxiety-like behavioral outcome in an open-field environment. 
Table 1. Open field behavioral parameters recorded at the end of 14-day intranasal daily dosing with vehicle or S100A9 aggregates in 12 -month old C57 Bl 6 mice.

\begin{tabular}{|c|c|c|c|c|}
\hline $\begin{array}{l}\text { Behavioral } \\
\text { parameters }\end{array}$ & $\begin{array}{l}\begin{array}{l}\text { Vehicle } \\
\text { control }\end{array} \\
n=10\end{array}$ & $\begin{array}{c}\text { S100A9 } \\
\text { fibrillar } \\
\text { aggregates } \\
\mathbf{n}=10\end{array}$ & $\begin{array}{c}\text { S100A9 } \\
\text { oligomeric } \\
\text { aggregates } \\
n=10\end{array}$ & $\begin{array}{c}\text { Kruskal-Wallis } \\
\text { ANOVA }\end{array}$ \\
\hline $\begin{array}{l}\text { Total Locomotor } \\
\text { Distance }(\mathrm{cm}) \\
\text { (mean }\end{array}$ & $1439.1 \pm 118.8$ & $1642.6 \pm 79.1$ & $1652.8 \pm 70.1$ & $\begin{array}{c}\mathrm{H}(2, \mathrm{~N}=30) \\
=2.006947 \\
(P=0.3666)\end{array}$ \\
\hline $\begin{array}{c}\text { Cumulative } \\
\text { Ambulation Time (s) } \\
\text { (mean } \pm \text { sem) }\end{array}$ & $88.6 \pm 10.2$ & $76.4 \pm 5.5$ & $65.9 \pm 5.1$ & $\begin{array}{c}\mathrm{H}(2, \mathrm{~N}=30) \\
=3.829396 \\
(P=0.1474)\end{array}$ \\
\hline $\begin{array}{c}\text { Cumulative } \\
\text { Ambulation Time (s) } \\
\text { (mean } \pm \text { sem) }\end{array}$ & $107.0 \pm 7.9$ & $128.9 \pm 5.1$ & $134.7 \pm 4.6$ & $\begin{array}{l}\mathrm{H}(2, \mathrm{~N}=30) \\
=4.761425 \\
(P=0.0925)\end{array}$ \\
\hline $\begin{array}{c}\text { Ambulation Speed } \\
\text { (cm/s) } \\
(\text { mean } \pm \text { sem })\end{array}$ & $12.8 \pm 0.3$ & $12.6 \pm 0.2$ & $12.3 \pm 0.5$ & $\begin{array}{c}\mathrm{H}(2, \mathrm{~N}=30) \\
=2.029224 \\
(P=0.3625)\end{array}$ \\
\hline $\begin{array}{c}\text { Vertical Rearing } \\
\text { (incidence) } \\
\text { (meantsem) }\end{array}$ & $26.8 \pm 6.2$ & $29.7 \pm 3.1$ & $25.6 \pm 3.5$ & $\begin{array}{l}\mathrm{H}(2, \mathrm{~N}=30) \\
=0.8797098 \\
(P=0.6441)\end{array}$ \\
\hline
\end{tabular}




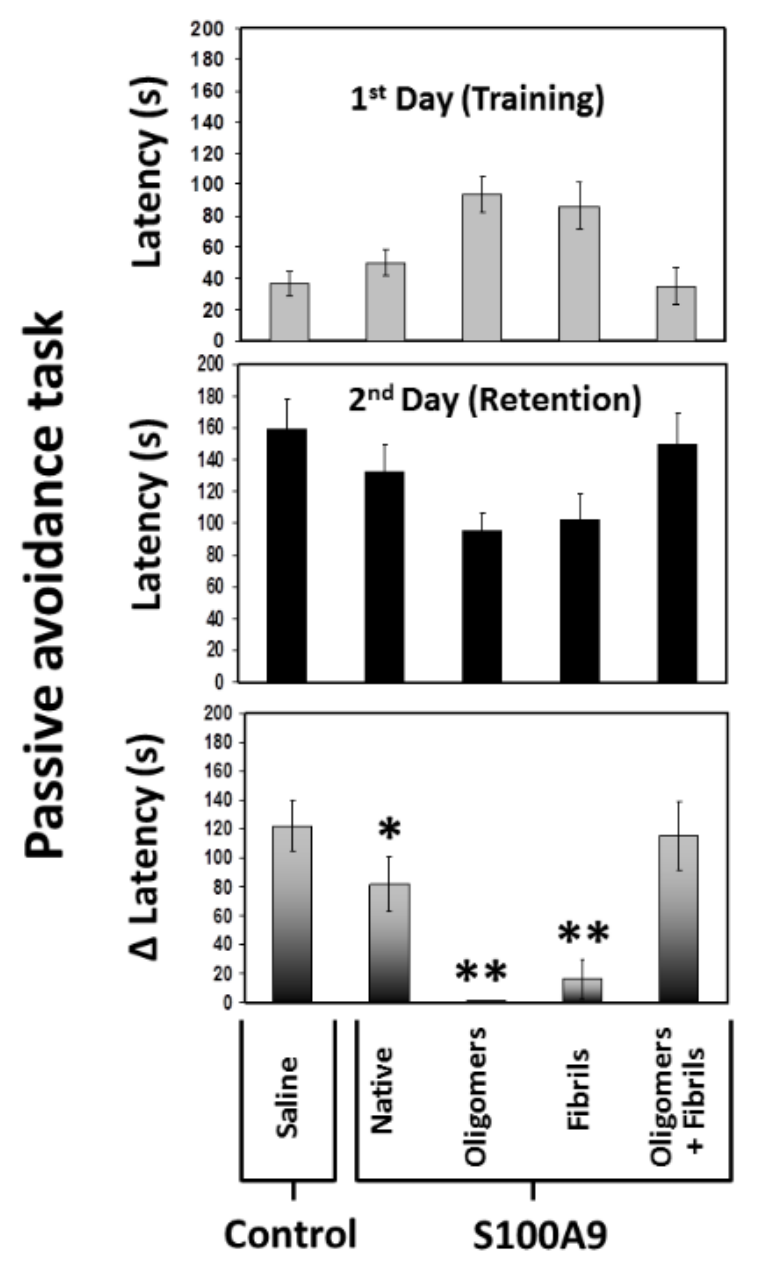

Fig. 3. Behavioural effects of intranasal dosing with S100A9 species in 12-month old C57Bl/6 mice on the passive avoidance task $1^{\text {st }}$ day (training) and $2^{\text {nd }}$ day (retention) latencies $(s)$ plus the latency differences ( $\Delta$ latencies, $s$ ).

Animal groups $(\mathrm{n}=14)$ were intranasally administered saline or S100A9 species daily for 14 days and passive avoidance performance was tested on protocol days $15\left(1^{\text {st }}\right.$ day - training $)$ and day $16\left(2^{\text {nd }}\right.$ day - retention $) . ~ P \mathrm{P}<0.05 ; * * \mathrm{P}<0.01$ compared with control. 
3.3. Neurochemical assay of hippocampal NA, 5-HT and the metabolite 5-HIAA after 14day treatment with S100A9 monomers, oligomers, fibrils and the oligomer/fibril mixture

There were no significant changes in NA, 5-HT or 5HIAA levels in hippocampal tissues in all animal groups treated with S100A9 species (Table 2).

Table 2. Hippocampal levels (\% control) of NA, 5-HT and its metabolite 5-HIAA as well as 5$\mathrm{HIAA} / 5-\mathrm{HT}$ ratios in 12 -monthold $\mathrm{C} 57 \mathrm{Bl} / 6$ mice following intranasal dosing with $\mathrm{S} 100 \mathrm{~A} 9$ species.

\begin{tabular}{|c|c|c|c|c|}
\hline \multirow[t]{2}{*}{ Animal group } & \multicolumn{3}{|c|}{$\%$ control } & \multirow[b]{2}{*}{ 5-HIAA/5-HT } \\
\hline & NA & 5-HT & 5-HIAA & \\
\hline Native S100A9 & $97.0 \pm 1.9$ & $108.6 \pm 3.7$ & $107.4 \pm 3.1$ & $100.0 \pm 0.8$ \\
\hline $\begin{array}{c}\text { S100A9 } \\
\text { oligomers }\end{array}$ & $88.4 \pm 1.8$ & $98.2 \pm 3.3$ & $104.6 \pm 3.0$ & $107.1 \pm 0.9$ \\
\hline S100A9 fibrils & $95.5 \pm 1.9$ & $98.5 \pm 3.3$ & $108.5 \pm 3.1$ & $109.5 \pm 0.9$ \\
\hline $\begin{array}{c}\text { Mixture S100A9 } \\
\text { oligomers }+ \\
\text { fibrils }\end{array}$ & $99.5 \pm 2.0$ & $109.8 \pm 3.7$ & $102.1 \pm 2.9$ & $95.2 \pm 0.8$ \\
\hline
\end{tabular}

3.4. Neurochemical assay of hippocampal DA and the metabolites DOPAC, HVA after 14day treatment with native S100A9, oligomers, fibrils and the oligomer/fibril mixture

There was a $-49.5 \%(P<0.05)$ decrease in DA levels in the hippocampus induced by 14-day i.n. treatment with S100A9 oligomers but in contrast, mice dosed with S100A9 fibrils displayed an increase in DA levels $(+44.1 \%, P<0.05)$ (Fig. 4). No significant changes were noted in response to native S100A9 two week treatment although the HVA concentration in 
the hippocampus was doubled $(P<0.01)$ following native S100A9 chronic dosing (Fig. 4). The hippocampal DA content in the animal group chronically treated with the oligomeric/fibrillar combination displayed a reduction of $25 \%$ in contrast there were no significant changes in HVA level in response to oligomeric or fibrillar treatment. In all groups of animals there were no detectable alterations in hippocampal DOPAC concentrations (Fig. 4).

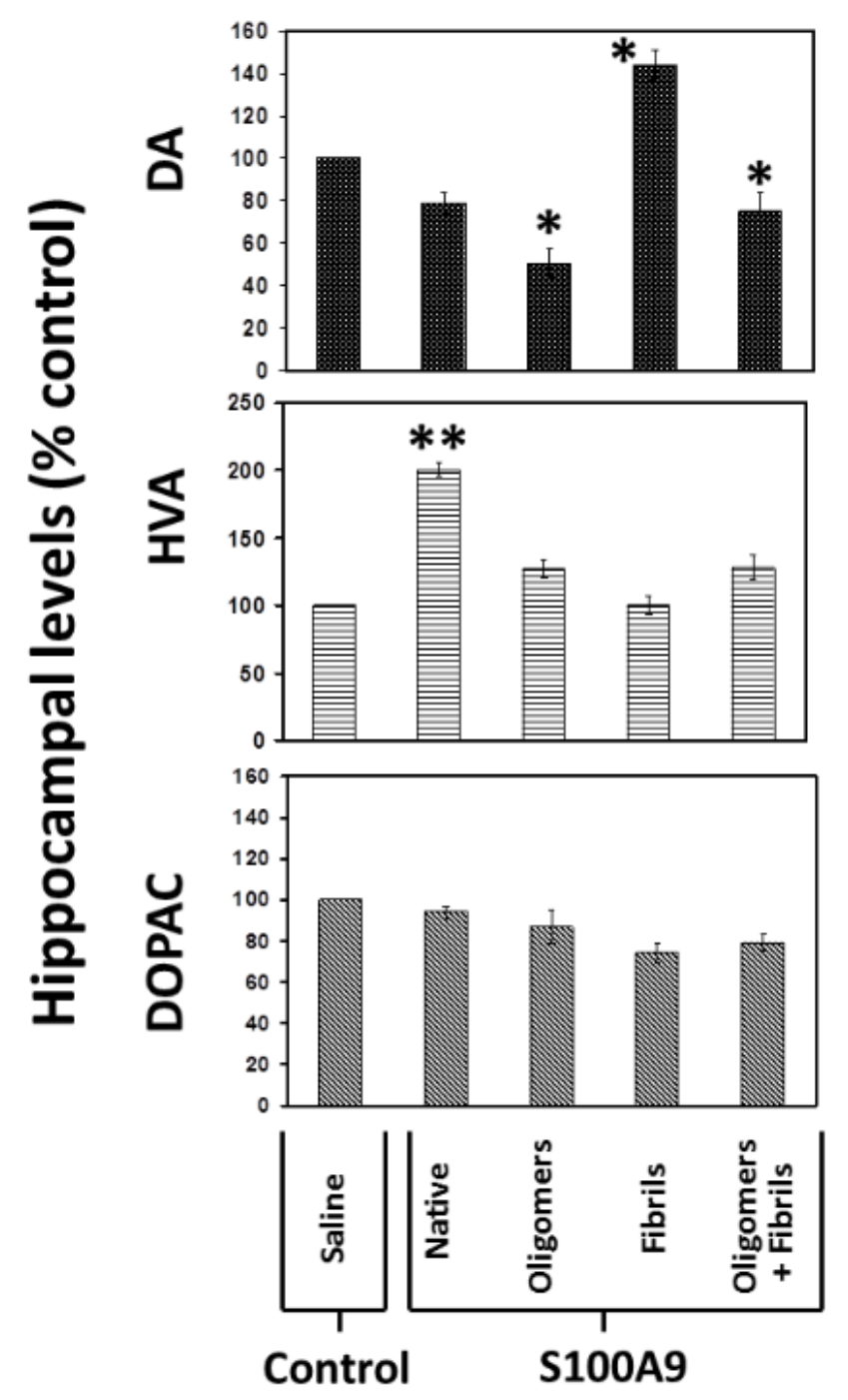

Fig. 4. Hippocampal levels of DA, HVA and DOPAC measured in 12-month old C57Bl/6 mice following intranasal dosing with S100A9 species.

Animal groups $(n=14)$ were intranasally administered saline or S100A9 species daily for 14 days and hippocampal DA, HVA and DOPAC levels were measured as \% of control (DA control $=0.28 \pm$ $0.11 \mathrm{nM} / \mathrm{g}$ of tissue; HVA control $=0.11 \pm 0.03 \mathrm{nM} / \mathrm{g}$ of tissue; DOPAC control $=0.38 \pm 0.10 \mathrm{nM} / \mathrm{g}$ of tissue).

$* \mathrm{P}<0.05$ compared to control. 
3.5. Neurochemical assay of prefrontal cortical NA, 5-HT and the metabolite 5-HIAA after 14-day treatment with native S100A9, oligomers, fibrils and the oligomer/fibril mixture

In the case of NA levels in the prefrontal cortex, only treatment with native S100A9 evoked a statistically significant decrease $(-45.6 \%, \mathrm{P}<0.05)$ (Table 3). In all other S100A9 species treated groups, there were no significant changes in NA concentration in the prefrontal cortex. Moreover, monomeric S100A9 administration reduced the 5-HT content by $-46.3 \%$ $(P<0.05)$ in the prefrontal cortex (Table 3$)$ whereas oligomers, fibrils or their combination respectively varied 5 -HT levels by $+15.4 \%,+12.9 \%$ or $+17.0 \%$ though none of these fluctuations achieved statistical significance (Table 3).

Native S100A9 administration decreased $(-45.5 \%, \mathrm{P}<0.05)$ prefrontal cortical levels of 5HIAA (Table 3). Conversely S100A9 fibrillar treatment did not cause any significant change in 5-HIAA concentration and neither did the oligomers nor the combinative treatment have any influence on levels of this metabolite. 
Table 3. Prefrontal cortical levels (\% control) of NA 5-HT andits metabolite 5-HIAA as well as.

5-HIAA/5-HTratios in 12-month old C57B/ 6 mice followingintranasal dosing with S100A2.

species.

\begin{tabular}{|c|c|c|c|c|}
\hline \multirow[b]{2}{*}{ Animal group } & \multicolumn{4}{|c|}{$\%$ control } \\
\hline & NA & 5-HT & 5-HIAA & 5-HIAA/5-HT \\
\hline Native S100A9 & $54.4 \pm 1.4^{*}$ & $53.7 \pm 2.1^{*}$ & $54.5 \pm 0.9 *$ & $100.0 \pm 0.0$ \\
\hline $\begin{array}{l}\text { S100A9 } \\
\text { oligomers }\end{array}$ & $92.1 \pm 2.7$ & $115.4 \pm 4.6$ & $100.6 \pm 1.6$ & $134.3 \pm 3.1$ \\
\hline S100A9 fibrils & $99.2 \pm 2.3$ & $112.9 \pm 4.5$ & $116.7 \pm 1.8$ & $141.1 \pm 3.0 *$ \\
\hline $\begin{array}{c}\text { Mixture S100A9 } \\
\text { oligomers + } \\
\text { fibrils }\end{array}$ & $98.2 \pm 2.6$ & $117.0 \pm 4.6$ & $100.7 \pm 1.6$ & $134.4 \pm 2.5$ \\
\hline
\end{tabular}

3.6. Neurochemical assay of prefrontal cortical DA and the metabolites DOPAC, HVA after 14-day treatment with native S100A9, oligomers, fibrils and the oligomer/fibril mixture

Two week nasal administration of native S100A9 produced a fall $(-37.8 \%, P<0.05)$ in DA prefrontal cortical concentration and S100A9 oligomer treatment gave a similar decrement ($30.2 \%, P<0.05)$. Conversely, S100A9 fibril or oligomer/fibril combination dosing had no significant effect on DA levels. Native S100A9 reduced cortical DOPAC concentrations ($46.2 \%, P<0.05)$ whilst S100A9 fibrils increased DOPAC levels $(+19.6 \%, \mathrm{P}<0.05)$ but combinative fibril/oligomer administration had no significant action on DOPAC prefrontal cortical level (Fig. 5). 


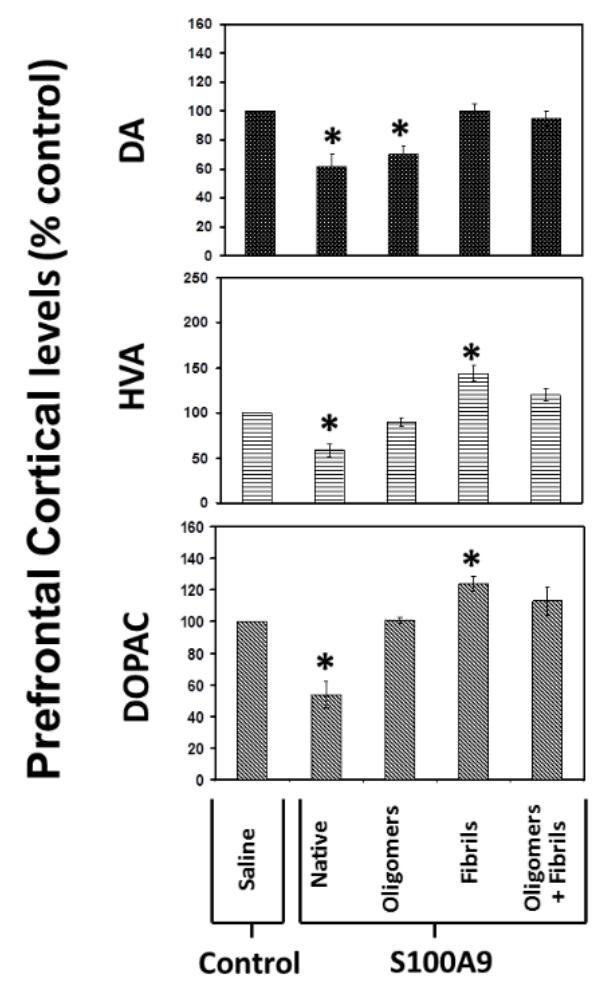

Fig. 5. Prefrontal cortical levels of DA, HVA and DOPAC measured in 12-month old C57Bl/6 mice following intranasal dosing with S100A9 species.

Animal groups $(n=14)$ were intranasally administered saline or S100A9 species daily for 14 days and prefrontal cortical DA, HVA and DOPAC levels were measured as \% of control (DA control $=1.72 \pm 0.42 \mathrm{nM} / \mathrm{g}$ of tissue; HVA control $=0.41 \pm 0.05 \mathrm{nM} / \mathrm{g}$ of tissue; DOPAC control $=0.78 \pm 0.06 \mathrm{nM} / \mathrm{g}$ of tissue). $* \mathrm{P}<0.05$ compared to control.

3.7. DOPAC/DA, HVA/DA and 5-HIAA/5-HT ratios in the hippocampus of mice after 14day intranasal treatment with S100A9 monomers, oligomers, fibrils and the oligomer/fibril mixture

The hippocampal DOPAC/DA ratio following S100A9 oligomer two-week intranasal delivery produced an increase $(+124.3 \%, P<0.01)$ in this parameter while the combination of S100A9 oligomer plus fibril treatment decreased this ratio by $-27.8 \%(P<0.05)$. Neither native S100A9 nor fibrils modified the DOPAC/DA ratio in the hippocampus (Fig. 6A).

Native S100A9 induced an increment in hippocampal HVA/DA ratio $(+52.8 \%, \mathrm{P}<0.05)$ along with a S100A9 oligomer boost in this ratio $(+172.2 \%, \mathrm{P}<0.01)$ (Fig. 6A). The fibrils of S100A9 also augmented $(+53.7 \%, \mathrm{P}<0.05)$ HVA/DA ratio whilst the oligomer/fibril 
combination had no effect (Fig. 6A). In comparison with controls, there were no 5-HIAA/5HT ratio hippocampal changes in any of the S100A9 species treated animals (Table 2).

3.8. DOPAC/DA, HVA/DA and 5-HIAA/5-HT ratios in the prefrontal cortex of mice after 14-day intranasal treatment with S100A9 monomers, oligomers, fibrils and the oligomer/fibril mixture

Following native S100A9 administration, a decrease $(-35.8 \%, \mathrm{P}<0.05)$ in DOPAC/DA ratio occurred in the prefrontal cortex but the S100A9 oligomer/fibril combination produced a $+72.5 \%(P<0.05)$ increase (Fig. 6B).

Intranasal delivery of native S1009 decreased the prefrontal cortical HVA/DA ratio by $38.8 \%(\mathrm{P}<0.05)$. In contrast, fibrils of $\mathrm{S} 100 \mathrm{~A} 9$ elevated the HVA/DA ratio $(+42.3 \%$, $\mathrm{P}<0.05)$ and the oligomer/fibril mixture also evoked an increase $(+40.7 \%, \mathrm{P}<0.05)$ (Fig. 6B).

Fourteen day administration of native S100A9 did not alter prefrontal cortical 5-HIAA/5-HT ratios compared to controls (Table 3). However, delivery of S100A9 oligomers, fibrils and their combination all induced respective escalations compared to controls of $+34.3 \%$, $+41.1 \%$ and $+34.4 \%(\mathrm{P}<0.05)$ in these ratios reflecting an apparent increased 5-HT turnover in response to these particular species within the prefrontal cortex (Table 3). 

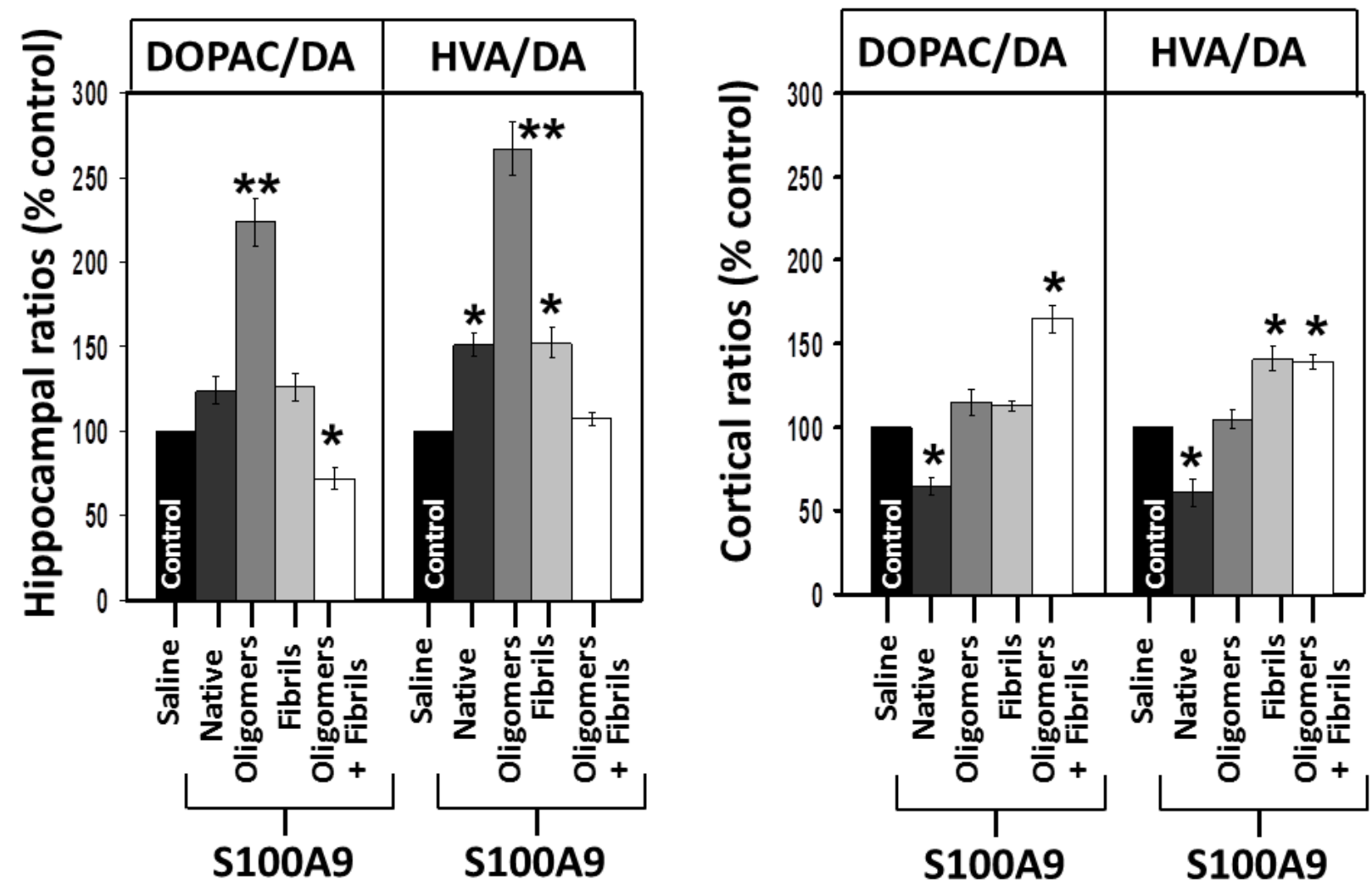

Fig. 6. (A) Hippocampal and (B) prefrontal cortical DOPAC/DA and HVA/DA ratios calculated for 12-month old C57Bl/6 mice following intranasal dosing with S100A9 species.

Animal groups $(n=14)$ were intranasally administered saline or S100A9 species daily for 14 days and hippocampal and prefrontal cortical DOPAC/DA and HVA/DA ratios were calculated as $\%$ of control (All controls $=100 \%)$. ${ }^{*} \mathrm{P}<0.05 ; * * \mathrm{P}<0.01$ compared to control.

\section{Discussion}

Memory deficits may develop from a variety of neuropathologies and the pathological selfassembly of proteins and peptides into amyloid species is a defining characteristic of a group of more than twenty human diseases [47-49] including neurodegenerative conditions such as $\mathrm{AD}$ [50]. The amyloid hypothesis postulates that proteins which undergo aberrant physiological folding generate toxic oligomeric species capable of inducing a decline in synaptic plasticity, perturbation of neuronal networks and cell death [24,51] instigating cognitive dysfunction. Moreover, along with oligomeric species, amyloid fibrils are invariably present in affected biosystems. Many studies have shown that soluble oligomeric assemblies, which either precede amyloid formation or exist as stand-alone species are formed in parallel with fibrils to exert the most potent detrimental physiological effects [52]. 
In the case of $\mathrm{AD}$, aggregation of $\mathrm{A} \beta$ peptide has been identified and is initiated by the misfolding of the native protein monomer into an amyloid form of insoluble fibrils. Additionally, fibrillar (but not native) forms of $A \beta$ peptide which are akin to those present in $\mathrm{AD}$ amyloid plaques, are toxic in neuronal cell culture [53,54]. However, a relatively weak association has been unveiled between fibrillar plaque density in $\mathrm{AD}$ brains and dementia severity, whereas correlations between soluble $A \beta$ levels and the extent of synaptic loss coupled with cognitive impairment are somewhat stronger [54,55]. SDS-stable A $\beta$ oligomers (relative molecular masses $\mathrm{Mr} \approx 8,000$ and 12,000) have been detected by Western blotting in the buffer-soluble fraction of AD cortical areas [56]. It has also been reported that $A \beta$ oligomers, in the absence of monomers and amyloid fibrils, disrupt synaptic plasticity in vivo at concentrations corresponding to those found in human brain and cerebrospinal fluid [54]. Subsequently, it was proposed that cerebral amyloidosis predicts longitudinal episodic memory decline in presymptomatic AD but multidomain cognitive decline in the symptomatic AD stage. Findings of this nature imply that amyloidosis in the brain is an indicator of early cognitive decline and they provide a useful outcome measure for early assessment and prevention treatment trials [21]. In this connection, the observation that S100A9 is abundant in tissues surrounding amyloid deposits in $\mathrm{AD}$ brains is highly suggestive that an elevation of S100A9 favours its aggregation and deposition [16,19,57].

After 14-days of native S100A9 treatment, there were no significant changes in passive avoidance latency, on the test day. Concomitantly, neither locomotor activity nor emotionality (anxiety-like behavior) was perturbed in any of the treatment groups so the passive avoidance disruption induced by S100A9 aggregates during retention was an exclusive cognitive phenomenon. Simultaneously, in the prefrontal cortex, the overall neurochemical response was represented by a decrease in levels of DA, 5-HT, their respective metabolites DOPAC and 5-HIAA as well as NA in addition to DA turnover (DOPAC/DA and HVA/DA ratio). This finding was in contrast with the neurochemical outcome in the hippocampus where an increase in HVA/DA ratio indicated an elevation of DA turnover. It is likely that these neurochemical outputs originate from pro-inflammatory effects of native S100A9 protein [14,16]. It may be deduced therefore that chronic intranasal administration of monomeric S100A9 initiated an inflammatory response which then yielded the observed neurochemical changes in the affected brain structures. 
In fact, we have previously demonstrated that S100A9 can act as a link between the amyloid and inflammatory cascades [16] and during AD plaque formation microglia become activated and recruited to the plaque deposition sites [58] causing microgliosis. The activated microglia secrete S100A9 as well as an array of other pro- and anti-inflammatory mediators. This can contribute to changes in neuronal calcium homeostasis [59,60]. As a result, S100A9 expression in neuronal cells can also be turned on, which further activates microglia via the toll-like receptor 4 (TLR 4) and the receptor for advanced glycation end products (RAGE) signaling pathway $[61,62]$ there being an inflammatory repercussion.

Experimental evidence has shown that in animal models of $\mathrm{AD}$, mechanisms of cortical plasticity such as long-term potentiation (LTP) and long-term depression (LTD) are impaired, but in AD patients, LTP-like cortical plasticity is abolished whereas LTD seems to be preserved [28]. In the present case of S100A9 monomeric treatment of aged animals, despite there being a neurotransmitter malfunction, both mechanisms may not have yet been invoked. Hence, passive avoidance memory deficiency was not discernible in the current protocol, even though the prefrontal cortex is a brain area which is crucial for memory, attention, and decision making [63]. It could be reasoned that S100A9 monomers initiated inflammation to set off the prefrontal cortical neurochemical dysfunction which may in turn affect the functional connectivity between the hippocampus and prefrontal cortex known to be essential for memory formation [64-66].

The most striking effects were observed in the animal group with intranasally administered misfolded species of S100A9 protein. In the passive avoidance paradigm, mice which received S100A9 oligomeric structures expressed an increment of passive avoidance latency on the training day in comparison with controls though this difference was not maintained $24 \mathrm{~h}$ later in the testing procedure. Passive avoidance amnesia in this instance was associated with a decrement of DA concentration in both the prefrontal cortex and the hippocampus which was also accompanied by an increase in hippocampal DA turnover. Such concomitant neurochemical consequences substantiate the involvement of these neuroanatomical structures in processes underlying passive avoidance amnesia and identify the participation of DA-ergic pathways. The part played by the DA-ergic system in learning and memory mechanisms is recognized and DA transmission has been hypothesized as a governing factor for mechanisms of cortical plasticity in AD [28]. It also performs dual protective and toxic roles during neurodegeneration [67]. 
DA has wide-ranging effects on both cortical and subcortical brain regions and on many types of cognitive task that rely on a variety of different learning and memory systems [68]. Consideration of these details inevitably leads to different postulations as to how changes in brain dopamine metabolism following intranasal S100A9 oligomer administration cause passive avoidance memory impairment. In this case, it is appropriate to point out that the toxicity of S100A9 oligomers together with DA-ergic adverse effects are the foremost integral components of amnestic activity rather than the initial pro-inflamatory properties of the native protein monomers. It is becoming increasingly evident that deficits in the cortex and hippocampus during the early stages of $\mathrm{AD}$ dementia are associated with synaptic damage caused by toxic oligomers of amyloid- $\beta$ peptide $\left(\mathrm{A} \beta_{1-42}\right)$. In light of this, a novel mechanism has been designated for the regulation of synaptic transmission by $A \beta_{1-42}$ via disruption of the interaction between synaptophysin and vesicle-associated membrane protein 2 (VAMP2) [69]. Not long ago, it was reported that $\mathrm{A} \beta$ peptide in $\mathrm{AD}$ patients induces both metabolic and morphological changes in pyramidal neurons in the hippocampus and neocortex. Prefrontal and cingulate cortices together with the hippocampus also express changes during the early stage of the disease and are responsible for symptoms of cognitive decline [24,70]. Sub-cortical nuclei, 5-HT, NA and DAcontaining neurons constitute the monoaminergic ascending diffuse innervating system that synapses onto hippocampal and neocortical neurons, with several modulatory effects on neuronal firing [26]. Neuropathological studies have established a link between morphological and functional changes occurring in this monoaminergic ascending system, particularly in respect of NA and 5-HT pathways and the pathophysiology of AD [24-26]. In association with symptoms of cognitive decline, about $35-40 \%$ of AD patients present with extrapyramidal signs, supporting the concept that DA-containing neurons undergo degenerative changes [24,27].

Fibrillar S100A9 14-day treatment induced passive avoidance memory retention deficits in $87.3 \%$ of the animals which correlated with an enhancement of DA turnover in the prefrontal cortex, an increased DA level in the hippocampus and elevation of HVA/DA ratio. DA is a multifaceted neurotransmitter and different degrees of DA dysfunction can occur during the phases of $\mathrm{AD}$ [24]. Correspondingly, in the current study it was unequivocally demonstrated that S100A9 species influenced the DA-ergic system differentially. Furthermore, DA not only provides communication between nerve cells but it is implicated in motor control. If this signal transmission becomes disturbed, the 
consequences can be dramatic and this is illustrated by PD, the symptoms of which include akinesia and other movement disorders which can be traced back to a lack of DA [71]. It could be argued that a motor deficit might interfere with performance in the passive avoidance task but in this study there was no overt evidence of any decreased spontaneous locomotor activity to S100A9 aggregates. There have already been indications of the special role of DA and its receptors in forming long-lasting memories. For example, activation of the prefrontal cortical, striatal, and hippocampal dopamine $\mathrm{DA}_{1}$ - family of receptors $\left(\mathrm{D}_{1}\right.$ but not $\mathrm{D}_{5}$ receptors) is necessary for normal spatial information processing [72]. Reduced DA transporter (DAT) expression in the caudate putamen, hippocampus and frontal cortex has been described during human brain aging [73] and DAT has also been hypothesized as a possible target of amyloid insult [63]. Thus, an influence of S100A9 aggregates on DAT function cannot be excluded as one of the elements of DA disrupted function in spatial memory [74].

It may also be hypothesised that S100A9 fibrillar deposits in AD possess inflammatory properties which are linked to their intrinsic structure, most probably their cross- $\beta$ sheet structure similar to other species of protein fibrils, for example, $\alpha$-synuclein in PD. Since fibrils of other amyloids induce analogous immunological responses, it has been proposed that the acknowledged fibril specific cross- $\beta$ sheet structure represents a generic motif recognized by the innate immune system [75]. In the case of the amnesia caused by S100A9 fibrils, it may be suggested that fibrillar incited inflammation [76] or injury interferes with DA metabolism thereby contributing to memory impairment so a DA-ergic dysfunction may well be involved in cognitive decline [24].

Indeed, experimental data from transgenic AD mice showed how DA-ergic pathology and amyloid deposition are closely related, suggesting a causative effect of amyloid on dopamine dysfunction [77]. Moreover, the restoration of DA transmission has been shown to be conducive to memory and learning in an $\mathrm{AD}$ mouse model reinforcing the role of $\mathrm{DA}$ in cognitive tasks $[78,79]$. This has recently been linked to a demonstrated protective role, where DA has anti-amyloidogenic and anti-oxidant effects in the mouse brain [24,80].

In summary, there are two distinct components connected with the memory modifying activity of S100A9 species in the aging mice within this study. Firstly, native S100A9 which is more likely to possess pro-inflammatory properties [16] did not modify memory in the passive avoidance task. This occurred even though it evoked a general and consistent 
decrease in monoamine levels (DA, 5-HT and NA) and increased metabolic marker ratios of DA and 5-HT turnover (DOPAC/DA, HVA/DA and 5-HIAA) mainly in the prefrontal cortex. Secondly, S100A9 oligomers and fibrils administered separately induced amnesia accompanied by elevated DA turnover mainly in the hippocampus (Fig. 7) and though the fibrils did augment prefrontal cortical DA turnover, it was conceivable that this action was of secondary importance to the hippocampal response. The oligomer-fibril mixture behaved similarly to the fibrils administered alone but to a lesser degree and this may be attributable to the fact that both species in the mixture were matched to the total dose of the individual species in such a way that they were at half the combined concentration within the mixture.

These results provide insight into a novel pathogenetic mechanism underlying amnesia in a fear-aggravated memory task based on amyloidogenesis of a pro-inflammatory agent leading to disrupted brain neurochemistry in the aged brain. The data further suggests that amyloid species of S100A9 generate deleterious activity principally to the DA-ergic system and this finding might be potentially exploited during dementia management through a neuroprotective strategy.

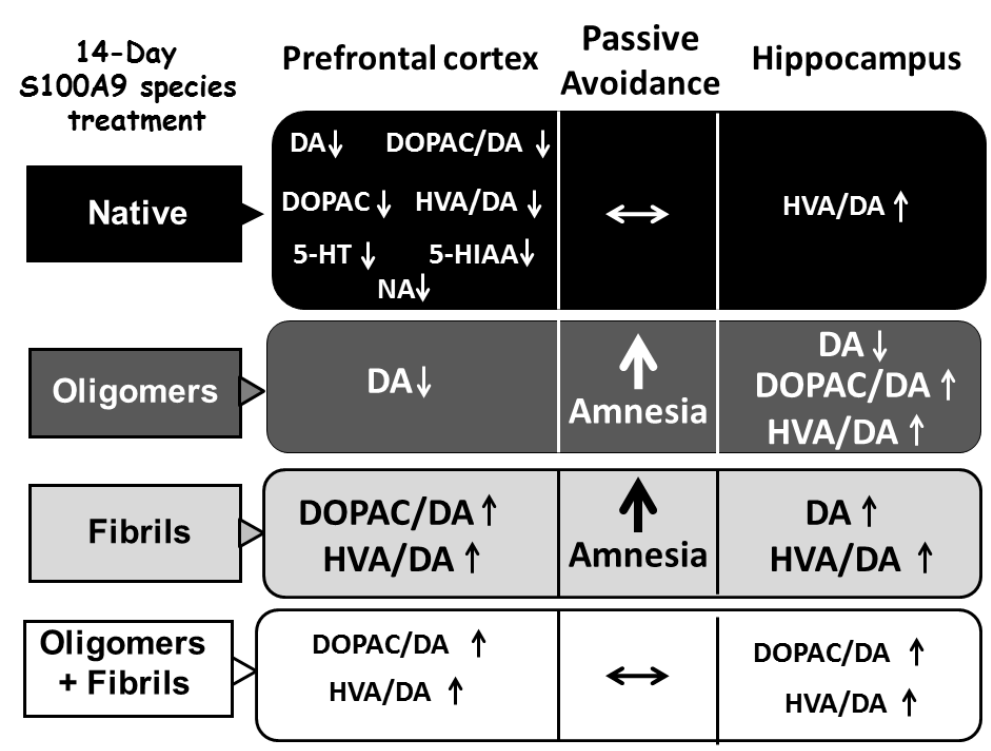

Fig. 7. Scheme summarising the significant hippocampal and prefrontal cortical neurochemical outcomes of 14-day intranasal administration of S100A9 species in 12-month old C57Bl/6 mice in relation to their passive avoidance performance.

Upward arrow $=$ increase downward arrow $=$ decrease; horizontal double headed arrow $=$ no change 


\section{Acknowledgements}

The authors are grateful for the funding for this work provided by the P. K. Anokhin Institute for Normal Physiology, Swedish Medical Research Council and FP-7 Marie Curie Action "Nano-Guard" 269138 to M.A.G. and L.A.M-R. We are deeply thankful to Rakez Kayed for the gift of A11 and fibrillary antibodies.

\section{References}

[1] Hoozemans JJ, Veerhuis R, Rozemuller JM, Eikelenboom P. Neuroinflammation and regeneration in the early stages of Alzheimer's disease pathology. Int $\mathrm{J}$ Dev Neurosci 2006;24:157-65.

[2] Gruden MA, Davydova TB, Malisauskas M, Zamotin VV, Sewell RDE, Voskresenskaya NI, et al. Autoimmune responses to amyloid structures of Abeta(25-35) peptide and human lysozyme in the serum of patients with progressive Alzheimer's disease. Dement Geriatr Cogn Disord 2004;18:165-71.

[3] Heneka MT, Carson MJ, El Khoury J, Landreth GE, Brosseron F, Feinstein DL, et al. Neuroinflammation in Alzheimer's disease. Lancet Neurol 2015;14:388-405. doi: 10.1016/S1474-4422(15)70016-5.

[4] De-Paula VJ, Radanovic M, Diniz BS, Forlenza OV. Alzheimer's disease. Subcell Biochem 2012;65:329-52. doi: 10.1007/978-94-007-5416-4_14.

[5] Braak H, Braak E. Neuropathological stageing of Alzheimer-related changes. Acta Neuropathol 1991;82:239-59.

[6] Crews L, Masliah E. Molecular mechanisms of neurodegeneration in Alzheimer's disease.

Hum Mol Genet 2010;19(R1):R12-20. doi: 10.1093/hmg/ddq160. 
[7] Sedaghat F, Notopoulos A. S100 protein family and its application in clinical practice. Hippokratia 2008;12:198-204.

[8] Donato R, Cannon BR, Sorci G, Riuzzi F, Hsu K, Weber DJ, Geczy CL. Functions of S100 proteins. Curr Mol Med 2013;13:24-57.

[9] Gruden MA, Davidova TB, Malisauskas M, Sewell RDE, Voskresenskaya NI, Wilhelm $\mathrm{K}$, et al. Differential neuroimmune markers to the onset of Alzheimer's disease neurodegeneration and dementia: autoantibodies to Abeta((25-35)) oligomers, S100b and neurotransmitters. J Neuroimmunol 2007;186:181-92.

[10] Mori T, Koyama N, Arendash GW, Horikoshi-Sakuraba Y, Tan J, Town T. Overexpression of human S100B exacerbates cerebral amyloidosis and gliosis in the $\mathrm{Tg} 2576$ mouse model of Alzheimer's disease. Glia 2010;58:300-14. doi: 10.1002/glia.20924.

[11] Afanador L, Roltsch EA, Holcomb L, Campbell KS, Keeling DA, Zhang Y, et al. The $\mathrm{Ca} 2+$ sensor S100A1 modulates neuroinflammation, histopathology and Akt activity in the PSAPP Alzheimer's disease mouse model. Cell Calcium 2014;56:68-80. doi: 10.1016/j.ceca.2014.05.002.

[12] Chang KA, Kim HJ, Suh YH. The role of S100A9 in the pathogenesis of Alzheimer's disease: the therapeutic effects of S100A9 knockdown or knockout. Neurodener Dis 2012;10:27-29.

[13] Roth J, Vogl T, Sorg C, Sunderkötter C. Phagocyte-specific S100 proteins: a novel group of proinflammatory molecules. Trends Immunol 2003;24:155-58.

[14] Ryckman C, Vandal K, Rouleau P, Talbot M, Tessier PA. Proinflammatory activities of S100: proteins S100A8, S100A9, and S100A8/A9 induce neutrophil chemotaxis and adhesion. J Immunol 2003;170:3233-42.

[15] Shepherd CE, Goyette J, Utter V, Rahimi F, Yang Z, Geczy CL, et al. Inflammatory S100A9 and S100A12 proteins in Alzheimer's disease. Neurobiol Aging 2006;27:1554-163. doi:10.1016/j.neurobiolaging.2005.09.033 
[16] Wang C, Klechikov AG, Gharibyan AL, Wärmländer SK, Jarvet J, Zhao L, et al. The role of pro-inflammatory S100A9 in Alzheimer's disease amyloid-neuroinflammatory cascade. Acta Neuropathol 2014;127:507-22. doi 10.1007/s00401-013-1208-4

[17] McGeer EG, McGeer PL. Neuroinflammation in Alzheimer's disease and mild cognitive impairment: a field in its infancy. J Alzheimer's Dis 2010;19:355-61. doi:10.3233/JAD-2010-19

[18] Cole GM, Frautschy SA. Mechanisms of action of non-steroidal anti-inflammatory drugs for the prevention of Alzheimer's disease. CNS Neurol Disord Drug Targets 2010;9:140-48.

[19] Vogl T, Gharibyan AL, Morozova-Roche LA. (2012) Pro-inflammatory S100A8 and S100A9 proteins: self-assembly into multifunctional native and amyloid complexes. Int J Mol Sci 13: 2893-2917.

[20] Carvalho SB, Botelho HM, Leal SS, Cardoso I, Fritz G, Gomes CM. Intrinsically disordered and aggregation prone regions underlie beta-aggregation in S100 proteins. PLoS One 2013;8(10):e76629. doi:10.1371/journal.pone.0076629

[21] Tiwari MK, Kepp KP. $\beta$-Amyloid pathogenesis: Chemical properties versus cellular levels. Alzheimers Dement 2015; pii: S1552-5260(15)02150-0. doi: 10.1016/j.jalz.2015.06.1895

[22] Ha TY, Chang KA, Kim J, Kim HS, Kim S, Chong YH, et al. S100a9 knockdown decreases the memory impairment and the neuropathology in $\mathrm{Tg} 2576$ mice, AD animal model. PLoS One 2010;5:e8840. http://dx.doi.org/10.1371/journal.pone.0008840

[23] Kim HJ, Chang KA, Ha TY, Kim J, Ha S, Shin KY, et al. S100A9 knockout decreases the memory impairment and neuropathology in crossbreed mice of $\mathrm{Tg} 2576$ and S100A9 knockout mice model. PLoS One 2014;9(2):e88924. doi: 10.1371/journal.pone.0088924. eCollection 2014.

[24] Martorana, A, Koch G. "Is dopamine involved in Alzheimer's disease?" Front Aging Neurosci 2014;6:252. doi: 10.3389/fnagi.2014.00252. 
[25] Simic G, Stanic G, Mladinov M, Jovanov-Milosevic N, Kostovic I, Hof PR. Does Alzheimer's disease begin in the brainstem? Neuropathol Appl Neurobiol 2009;35:532-54.

[26] Trillo L, Das D, Hsieh W, Medina B, Moghadam S, Lin B, et al. Ascending monoaminergic systems alterations in Alzheimer's disease. translating basic science into clinical care. Neurosci Biobehav Rev 2013;37:1363-69.

[27] Lopez OL, Wisnieski SR, Becker JT, Boller F, DeKosky ST. Extrapyramidal signs in patients with probable Alzheimer disease. Arch Neurol 1997;54:969-75. doi: 10.1001/archneur.1997.00550200033007ferences

[28] Koch G, Di Lorenzo F, Bonnì S, Giacobbe V, Bozzali M, Caltagirone C, et al. Dopaminergic modulation of cortical plasticity in Alzheimer's disease patients. Neuropsychopharmacology 2014;39:2654-2661. doi: 10.1038/npp.2014.119.

[29] Strac DS, Muck-Seler D, Pivac N. Neurotransmitter measures in the cerebrospinal fluid of patients with Alzheimer's disease: a review. Psychiatr Danub 2015;27:14-24.

[30] Zhang C, Liu Y, Gilthorpe J, van der Maarel JR. MRP14 (S100A9) protein interacts with Alzheimer beta-amyloid peptide and induces its fibrillization. PLoS One 2012;7:e32953 http://dx.doi.org/10.1371/journal.pone.0032953

[31] Ibrahim ZA, Armour CL, Phipps S, Sukkar MB. RAGE and TLRs: relatives, friends or neighbours? Mol Immunol 2013;56:739-44. doi: 10.1016/j.molimm.2013.07.008.

[32] Narumi K, Miyakawa R, Ueda R, Hashimoto H, Yamamoto Y, Yoshida T, et al. Proinflammatory proteins S100A8/S100A9 activate NK Cells via interaction with RAGE. J Immunol 2015;194:5539-48. doi: 10.4049/jimmunol.1402301.

[33] Fritz G, Botelho HM, Morozova-Roche LA, Gomes CM. Natural and amyloid selfassembly of S100 proteins: structural basis of functional diversity FEBS J 2010;277:457890. doi:10.1111/j.1742-4658.2010.07887.x

[34] Vogl T, Leukert N, Barczyk K, Strupat K, Roth J. Biophysical characterization of S100A8 and S100A9 in the absence and presence of bivalent cations. Biochim Biophys Acta 
[35] LeVine H. Thioflavine $\mathrm{T}$ interaction with synthetic Alzheimer's disease beta-amyloid peptides: detection of amyloid aggregation in solution. Protein Sci 1993;2:404-10.

[36] Yamada K, Santo-Yamada Y, Wada K. Stress-induced impairment of inhibitory avoidance learning in female neuromedin B receptor deficient mice. Physiol Behav 2003;78:303-309.

[37] Akar F, Mutlu O, Celikyurt IK, Bektas E, Tanyeri P, Ulak G, et al. Effects of 7-NI and ODQ on memory in the passive avoidance, novel object recognition, and social transmission of food preference tests in mice. Med Sci Monit Basic Res 2014;20:27-35.

doi: 10.12659/MSMBR.890438

[38] Lalonde R, Strazielle C. Relations between open-field, elevated plus-maze, and emergence tests as displayed by C57/BL6J and BALB/c mice. J Neurosci Meth 2008; 171:48-52. doi:10.1016/j.jneumeth.2008.02.003

[39] Bryan KJ, Lee H-g, Perry G, Smith MA, Casadesus G. Transgenic mouse models of Alzheimer's disease: behavioral testing and considerations In: Methods of Behavior Analysis in Neuroscience. Ed Buccafusco JJ, Boca Raton (FL): CRC Press/Taylor \& Francis; 2009. 2nd edition

[40] Sedelis M, Schwarting RK, Huston JP. Behavioral phenotyping of the MPTP mouse model of Parkinson's disease. Behav Brain Res 2001;125:109-25.

[41] Tillerson JL, Caudle WM, Reverón ME, Miller GW. Detection of behavioural impairments correlated to neurochemical deficits in mice treated with moderate doses of 1methyl-4-phenyl-1,2,3,6-tetrahydropyridine. Exp Neurol 2002;178:80-90.

[42] Gruden MA, Davidova TV, Yanamandra K, Kucheryanu VG, Morozova-Roche LA, Sherstnev VV, et al. Nasal inoculation with $\alpha$-synuclein aggregates evokes rigidity, locomotor deficits and immunity to such misfolded species as well as dopamine. Behav Brain Res 2013;243:205-12. doi: 10.1016/j.bbr.2013.01.011 
[43] Ben-Sreti MM, Sewell RDE, Upton N. Some observations on the effects of two enantiomers of two benzomorphan narcotic antagonists and atropine on analgesia, tremor and hypothermia produced by oxotremorine. Arch Int Pharmacodyn Ther 1982;256:219227.

[44] Prut L, Belzung C. The open field as a paradigm to measure the effects of drugs on anxiety-like behaviors: A review. Eur J Pharmacol. 2003;463:3-33.

[45] Ugrumov MV, Khaindrava VG, Kozina EA, Kucheryanu VG, Bocharov EV, Kryzhanovsky GN, et al. Modeling of preclinical and clinical stages of Parkinson's disease in mice. Neurosci 2011;181:175-178.

[46] Kayed R, Head E, Sarsoza F, Saing T, Cotman CW, Necula M, et al. Fibril specific, conformation dependent antibodies recognize a generic epitope common to amyloid fibrils and fibrillar oligomers that is absent in prefibrillar oligomers. Mol Neurodegener 2007;2:18. doi: $10.1186 / 1750-1326-2-18$

[47] Luheshi LM, Dobson CM. Bridging the gap: from protein misfolding to protein misfolding diseases. FEBS Lett 2009;583:2581-6. doi: 10.1016/j.febslet.2009.06.030.

[48] De Genst E, Messer A, Dobson CM. Antibodies and protein misfolding: From structural research tools to therapeutic strategies. Biochim Biophys Acta 2014;1844:190719. doi: 10.1016/j.bbapap.2014.08.016.

[49] Knowles TP, Vendruscolo M, Dobson CM. The amyloid state and its association with protein misfolding diseases. Nat Rev Mol Cell Biol 2014;15:384-96. doi: 10.1038/nrm3810.

[50] Thompson AJ, Barrow CJ. Protein conformational misfolding and amyloid formation: characteristics of a new class of disorders that include Alzheimer's and Prion diseases. Curr Med Chem 2002;9:1751-62.

[51] Hardy J, Selkoe DJ. The amyloid hypothesis of Alzheimer's disease: progress and problems on the road to therapeutics. Science 2002;297:353-356. doi: 10.1126/science.1072994

[52] Sipe JD, Benson MD, Buxbaum JN, Ikeda S, Merlini G, Saraiva MJ, et al. Amyloid fibril protein nomenclature: 2012 recommendations from the Nomenclature Committee of 
the International Society of Amyloidosis. Amyloid 2012;19:167-70. doi: $10.3109 / 13506129.2012 .734345$

[53] Pike CJ, Walencewicz AJ, Glabe CG, Cotman CW. In vitro aging of beta-amyloid protein causes peptide aggregation and neurotoxicity. Brain Res 1991;563;311-14.

[54] Walsh DM, Klyubin I, Fadeeva JV, Cullen WK, Anwyl R, Wolfe MS, et al. Naturally secreted oligomers of amyloid beta protein potently inhibit hippocampal long-term potentiation in vivo. Nature 2002;416:535-9. doi: 10.1038/416535a

[55] Lue, LF, Kuo YM, Roher AE, Brachova L, Shen Y, Sue L, et al. Soluble amyloid beta peptide concentration as a predictor of synaptic change in Alzheimer's disease. Am J Pathol 1999;155:853-62.

[56] McLean CA, Cherny RA, Fraser FW, Fuller SJ, Smith MJ, Beyreuther K, et al. Soluble pool of Abeta amyloid as a determinant of severity of neurodegeneration in Alzheimer's disease. Ann Neurol 1999;46:860-66.

[57] Zhao LN, Zhang T, Zhang C, Wang C, Morozova-Roche LA, Chew LY, et al. S100A9 induces aggregation-prone conformation in Abeta peptides: a combined experimental and simulation study. Roy Soc Chem Advances 2013;3(46): 24081-24089.

[58] Rogers J, Lue LF. Microglial chemotaxis, activation, and phagocytosis of amyloid betapeptide as linked phenomena in Alzheimer's disease. Neurochem Int 2001;39:333-340.

[59] Park KM, Yule DI, Bowers WJ. Tumor necrosis factor alpha potentiates intraneuronal $\mathrm{Ca} 2+$ signaling via regulation of the inositol 1,4,5-trisphosphate receptor. J Biol Chem 2008;283:33069-33079. doi:10.1074/jbc.M802209200.

[60] Yoshiyama Y, Higuchi M, Zhang B, Huang SM, Iwata N, Saido TC, et al. Synapse loss and microglial activation precede tangles in a P301S tauopathy mouse model. Neuron 2007;53(3):337-351. doi:10.1016/j.neuron.2007.01.010 
[61] Ryu MJ, Liu Y, Zhong X, Du J, Peterson N, Kong G, et al. Oncogenic Kras expression in postmitotic neurons leads to S100A8-S100A9 protein overexpression and gliosis. J Biol Chem 2012;287:22948-22958. doi:10.1074/jbc.M112.357772

[62] Schlachetzki JC, Hull M. Microglial activation in Alzheimer's disease. Curr Alzheimer Res 2009;6:554-563.

[63] Torkaman-Boutorabi A, Sheidadoust H, Hashemi-Hezaveh SM, Zarrindast MR. Influence of morphine on medial prefrontal cortex alpha2 adrenergic system in passive avoidance learning in rats. Pharmacol Biochem Behav. 2015;133:92-8. doi: 10.1016/j.pbb.2015.03.018.

[64] Floresco SB, Seamans JK, Phillips AG. Selective roles for hippocampal, prefrontal cortical, and ventral striatal circuits in radial-arm maze tasks with or without a delay. $\mathrm{J}$ Neurosci 1997;17(5):1880-90.

[65] Barker GR, Warburton EC. When is the hippocampus involved in recognition memory? J Neurosci 2011;31:10721-31.

[66] Colgin LL. Oscillations and hippocampal-prefrontal synchrony. Curr Opin Neurobiol 2011;21(3):467-74.

[67] Segura-Aguilar J, Paris I, Muñoz P, Ferrari E, Zecca L, Zucca FA. Protective and toxic roles of dopamine in Parkinson's disease. J Neurochem 2014;129:898-915. doi:10.1111/jnc. 12686 .

[68] Ashby FG, Valentin VV, von Meer SS. Differential effects of dopamine-directed treatments on cognition. Neuropsychiatr Dis Treat 2015;11:1859-1875. doi: 0.2147/NDT.S65875. eCollection 2015

[69] Russell CL, Semerdjieva S, Empson RM, Austen BM, Beesley PW, Alifragis P. Amyloid- $\beta$ acts as a regulator of neurotransmitter release disrupting the interaction between synaptophysin and VAMP2. PLoS One 2012;7:e43201. doi: 10.1371/journal.pone.0043201. 
[70] Sperling RA, Dickerson BC, Pihlajamaki M, Vannini P, LaViolette PS, Vitolo OV, et al. Functional alterations in memory networks in early Alzheimer's disease. Neuromolecular Med. 2010;2:27-43.

[71] Kucinski A, Albin RL, Lustig C, Sarter M. Modeling falls in Parkinson's disease: Slow gait, freezing episodes and falls in rats with extensive striatal dopamine loss. Behav Brain Res 2015;282:155-64. doi: 10.1016/j.bbr.2015.01.012.

[72] Sariñana J, Tonegawa S. Differentiation of Forebrain and Hippocampal Dopamine 1Class Receptors, D1R and D5R, in Spatial Learning and Memory. Hippocampus 2015 Jul 15. doi: 10.1002/hipo.22492. [Epub ahead of print]

[73] Bäckman L, Lindenberger U, Li SC, Nyberg L. Linking cognitive aging to alterations in dopamine neurotransmitter functioning: recent data and future avenues. Neurosci Biobehav Rev 2010;34:670-677. 10.1016/j.neubiorev.2009.12.008।

[74] Gruden MA, Davydova TV, Narkevich VB, Fomina VG, Wang C, Kudrin VS, et al. Noradrenergic and serotonergic neurochemistry arising from intranasal inoculation with $\alpha$ synuclein aggregates which incite parkinsonian-like symptoms Behav Brain Res 2015;279:191-201. doi: 10.1016/j.bbr.2014.11.001.

[75] Gustot A, Gallea JI, Sarroukh R, Celej MS, Ruysschaert JM, Raussens V. Amyloid fibrils are the molecular trigger of inflammation in Parkinson's disease. Biochem J 2015 Aug 13. pii: BJ20150617. [Epub ahead of print]

[76] Kametani F. S100A9/Mrp14 plays an important role in A $\beta$ amyloidosis enhancement. J Neurol Stroke 2014;1(2):00006 doi: 10.15406/jnsk.2014.01.00006

[77] Perez SE, Lazarov O, Koprich JB, Chen EY, Rodriguez-Menendez V, Lipton JW, et al. Nigrostriatal dysfunction in familial Alzheimer's disease-linked APPswe/PS1DeltaE9 transgenic mice. J Neurosci 2005;25:10220-10229 10.1523/JNEUROSCI.2773-05.2005

[78] Ambrée O, Richter H, Sachser N, Lewejohann L, Dere E, de Souza Silva MA, et al. Levodopa ameliorates learning and memory deficits in a murine model of Alzheimer's disease. Neurobiol Aging 2009;30:1192-1204 10.1016/j.neurobiolaging.2007.11.010 
[79] Guzmán-Ramos K, Moreno-Castilla P, Castro-Cruz M, McGaugh JL, Martínez-Coria $\mathrm{H}$, LaFerla FM, et al. Restoration of dopamine release deficits during object recognition memory acquisition attenuates cognitive impairment in a triple transgenic mice model of Alzheimer's disease. Learn Mem 2012;19:453-460 10.1101/lm.026070.112

[80] Himeno E, Ohyagi Y, Ma L, Nakamura N, Miyoshi K, Sakae N, et al. Apomorphine treatment in Alzheimer mice promoting amyloid- $\beta$ degradation. Ann Neurol 2011;69:248256. 10.1002/ana.22319 